\title{
FAKTOR-FAKTOR YANG BERHUBUNGAN DENGAN TINDAKAN MENGEMUDI TIDAK AMAN PADA SUPIR BUS SAMPRI TRAYEK MEDAN - DOLOK SANGGUL
}

\author{
Irmayani, ${ }^{1}$ Enaldihend Lumban Tobing ${ }^{2}$ \\ Institut Kesehatan Medistra \\ Jl. Sudirman No.38 Lubuk Pakam Kec. Lubuk Pakam Kab.Deli Serdang \\ e-mail: irmayani_ph06@yahoo.com
}

\begin{abstract}
One of cause accidents is human error, which reflected in the dangerous behavior of driving a bus. Errors and violations can cause an accident to the driver itself and will harm the people around him. Based on everyday phenomena, it can be seen that many motorists violate traffic signs. This behavior of breaking traffic signs is one example of aggressive driving behavior that can endanger other road users. This study aims to explain the factors associated with unsafe driving action on Bus Sampri Driver in Medan Route - Dolok Sanggul. This research is an observational analytic survey using cross sectional design. The research was conducted at PT. Samosir Pribumi Transport Medan in October 2017-April 2018. The population in this study were all Bus Sampri drivers, Medan Dolok Sanggul Route and all passengers with the Medan-Dolok Sanggul destination. The sample in this study were 64 people where 32 people came from bus drivers and 32 people came from passengers who were taken using quota sampling technique. The research instrument uses a questionnaire. Data were analyzed using chi-square test with a confidence level of 95\% (alpha = 5\%). The results showed that there was a relationship between duration of work $(p=0.024)$, work period ( $p=0.024)$, rest period $(p=0.024)$, work schedule $(p=0.035)$ with unsafe driving action. Drivers are advised to maintain health so that they do not experience physical or psychological health problems, be careful in driving and obey traffic signs so as not to endanger passengers.
\end{abstract}

Keywords: length of work, length of service, rest period, work schedule, unsafe driving action

\section{PENDAHULUAN}

Kecelakaan mengakibatkan kerugian yang sangat besar bagi perusahaan, penumpang, pekerja maupun pengguna jalan lainnya. Salah satu penyebab kecelakaan yaitu kesalahan manusia, yang tercermin dari tindakan berbahaya sewaktu mengemudikan bus. Kecelakaan yang terjadi pada pengemudi dapat disebabkan karena kesalahan dan pelanggaran yang dilakukan pengemudi yang dapat merugikan diri sendiri dan orang-orang disekitarnya (Hastuti dkk, 2013). Berdasarkan data yang diperoleh dari Dirjen Perhubungan
Darat tentang kecelakaan lalu lintas, pada tahun 2011 terdapat 109.776 kecelakaan dengan korban kecelakaan yang meninggal dunia sebanyak 31.185 orang. Tahun 2012 meningkat menjadi 117.949 kecelakaan dengan korban kecelakaan yang meninggal dunia sebanyak 29.544 orang, sedangkan pada tahun 2013 mengalami penurunan jumlah kecelakaan yaitu 100.105 dengan jumlah korban kecelakaan yang meninggal dunia sebanyak 26.416 (Kementerian Perhubungan Darat RI, 2014). 
Berdasarkan data yang dipeoleh dari PT. Samosir Pribumi Transport Medan, pada tahun 2014 terdapat 3 kecelakaan dengan korban jiwa 11 orang, tahun 2015 terdapat 2 kecelakaan dengan korban jiwa 12 orang, dan pada tahun 2016 meningkat menjadi 4 kecelakaan dengan korban jiwa 18 orang, sedangkan pada tahun 2017 mengalami penurunan jumlah kecelakaan yaitu 3 dengan korban jiwa 7 orang. Dari data di atas dapat dikatakan bahwa jumlah kecelakaan Bus Sampri dari tahun 2014 sampai tahun 2017 yang paling tinggi yaitu tahun 2016 dengan jenis kecelakaan tabrakan dengan korban jiwa 18 Orang. Total kecelakaan tahun 2014 sampai tahun 2017 yaitu 12 kecelakaan dan total korban jiwa sebanyak 48 Orang dimana 3 orang meninggal dunia dan 45 orang luka luka, dan juga ditemukan bahwa cara pengemudi Bus Sampri Trayek Medan - Dolok Sanggul dalam mengemudikan bus kurang aman yang dapat dilihat dari segi perilaku supir bus yang tidak menggunakan alat pelindung diri (safety belt) supir mengemudikan bus dengan kecepatan tinggi apabila jalan yang dilaluinya sepi, supir juga sering mengambil jalur kiri pada saat menyelip kendaraan lain seperti truk, atau menerobos lampu merah jika kondisi jalan memungkinkan untuk dilewati.

Rumusan masalah pada penelitian ini adalah apakah faktor yang berhubungan dengan tindakan mengemudi tidak aman pada Supir Bus Sampri Trayek Medan - Dolok Sanggul Tahun 2018?

Penelitian ini bertujuan untuk menjelaskan faktor-faktor yang berhubungan dengan tindakan mengemudi tidak aman pada Supir Bus Sampri Trayek Medan - Dolok Sanggul Tahun 2018.

\section{METODE}

Penelitian ini bersifat survey analitik observasional dengan menggunakan desain cross sectional. Penelitian dilakukan di PT. Samosir Pribumi Transport Medan pada bulan Oktober 2017-April 2018. Populasi pada penelitian ini adalah seluruh supir Bus Sampri Trayek Medan Dolok Sanggul dan seluruh penumpang dengan tujuan Medan-Dolok Sanggul. Sampel pada penelitian ini sebanyak 64 orang dimana 32 orang berasal dari supir bus dan 32 orang berasal dari penumpang yang diambil dengan menggunakan teknik kuota sampling. Instrumen penelitian menggunakan kuesioner. Data dianalisis dengan menggunakan uji chi-square dengan tingkat kepercayaan 95\% (alpha=5\%).

\section{HASIL}

\section{a. Gambaran Faktor-Faktor Mengemudi} Tidak Aman

Gambaran faktor - faktor yang berhubungan dengan tindakan mengemudi tidak aman yang diamati meliputi lama kerja, masa kerja, lama istirahat, dan jadwal kerja. Adapun distribusinya disajikan pada tabel 1 :

Tabel 1. Distribusi Faktor-Faktor yang Berhubungan dengan Tindakan Mengemudi Tidak Aman pada Supir Bus Sampri Trayek Medan - Dolok Sanggul

\begin{tabular}{|c|c|c|c|}
\hline No & $\begin{array}{c}\text { Faktor Tindakan } \\
\text { Mengemudi Tidak } \\
\text { Aman }\end{array}$ & $\mathbf{n}$ & $\%$ \\
\hline \multirow[t]{4}{*}{1} & Lama Kerja & & \\
\hline & $\leq 8 \mathrm{Jam}$ & 19 & 59,4 \\
\hline & $>8 \mathrm{Jam}$ & 13 & 40,6 \\
\hline & Total & 32 & 100,0 \\
\hline \multirow[t]{4}{*}{2} & Masa Kerja & & \\
\hline & Baru $\leq 3$ Tahun & 19 & 59,4 \\
\hline & Lama > 3 Tahun & 13 & 40,6 \\
\hline & Total & 32 & 100,0 \\
\hline \multirow[t]{4}{*}{3} & Lama Istirahat & & \\
\hline & $\leq 15$ Menit & 19 & 59,4 \\
\hline & $>15$ Menit & 13 & 40,6 \\
\hline & Total & 32 & 100,0 \\
\hline \multirow[t]{4}{*}{4} & Jadwal Kerja & & \\
\hline & Shift Pagi & 8 & 25,0 \\
\hline & Shift Sore & 24 & 75,0 \\
\hline & Total & 32 & 100,0 \\
\hline
\end{tabular}


Tabel 1 di atas menunujukkan bahwa berdasarkan lama kerja, mayoritas responden memiliki lama kerja $\leq 8$ jam sebanyak 19 orang $(59,4 \%)$, berdasarkan masa kerja, mayoritas responden memiliki masa kerja $\leq 3$ tahun sebanyak 19 orang $(59,4 \%)$, berdasarkan lama istirahat, mayoritas responden memiliki lama istirahat $\leq 15$ menit sebanyak 19 orang $(59,4 \%)$ dan jika dilihat dari jadwal kerja, mayoritas responden shift sore yaitu sebanyak 24 orang (75\%).

\section{b. Tindakan Mengemudi Tidak Aman}

Distribusi responden berdasarkan tindakan mengemudi tidak aman, dapat dilihat pada tabel 2 .

Tabel 2 Distribusi Responden Berdasarkan Tindakan Mengemudi Tidak Aman pada Supir Bus Sampri Trayek Medan - Dolok Sanggul

\begin{tabular}{lrr}
\hline $\begin{array}{c}\text { Tindakan Mengemudi } \\
\text { Tidak Aman }\end{array}$ & n & \% \\
\hline Ringan & 22 & 68,7 \\
Berat & 10 & 31,3 \\
\hline Total & $\mathbf{3 2}$ & $\mathbf{1 0 0 , 0}$ \\
\hline
\end{tabular}

Berdasarkan tabel 2. di atas menunjukkan bahwa dari 32 responden, mayoritas tindakan mengemudi tidak aman pada responden berada pada kategori ringan yaitu sebanyałasa 22 orang $(68,7 \%)$. Kerja

\begin{tabular}{|c|c|c|c|c|c|c|c|}
\hline & \multicolumn{4}{|c|}{ Tidak Aman } & \multirow[b]{3}{*}{$\mathbf{n}$} & \multirow[b]{3}{*}{$\%$} & \\
\hline & \multicolumn{2}{|c|}{ Ringan } & \multicolumn{2}{|c|}{ Berat } & & & \\
\hline & $\mathbf{N}$ & $\%$ & $\mathbf{n}$ & $\%$ & & & \\
\hline$\leq 8$ & 10 & 52,6 & 9 & 47,4 & 19 & 100, & \\
\hline Jam & & & & & & 0 & \\
\hline$>8$ & 12 & 92,3 & 1 & 7,7 & 13 & 100, & 0,024 \\
\hline Jam & & & & & & 0 & \\
\hline Total & 2 & 68 , & 1 & 31,2 & 32 & 100 & \\
\hline & 2 & 8 & 0 & & & & \\
\hline
\end{tabular}

Tabel 3 di atas menunjukkan bahwa nilai $\mathrm{p}=0,024<\mathrm{a}=0,05$ yang dapat disimpulkan bahwa terdapat hubungan lama kerja dengan tindakan mengemudi tidak aman pada supir Bus Sampri Trayek Medan-Dolok Sanggul.

d. Hubungan Masa Kerja Dengan Tindakan Mengemudi Tidak Aman pada Supir Bus Sampri Trayek Medan - Dolok Sanggul

Hubungan masa kerja dengan tindakan mengemudi tidak aman pada Supir Bus Sampri Trayek Medan - Dolok Sanggul tahun 2018, dapat dilihat pada tabel 4 berikut:

Tabel 4. Hubungan Masa Kerja Dengan

Tindakan Mengemudi Tidak Aman pada Supir Bus Sampri Trayek Medan - Dolok Sanggul

\section{Tindakan}

Mengemudi

Tidak Aman value

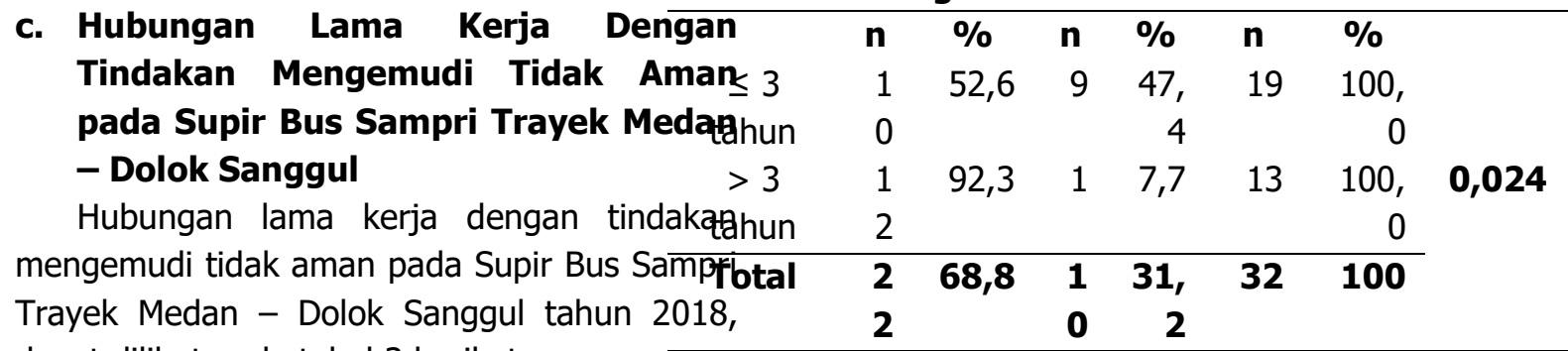
dapat dilihat pada tabel 3 berikut:

Tabel 4 di atas menunjukkan bahwa nilai

Tabel 3. Hubungan Lama Kerja dengan Tindakan Mengemudi Tidak Aman pada Supir Bus Sampri Trayek Medan - Dolok Sanggul

\begin{tabular}{llcc}
\hline Lama & Tindakan & Total & $\begin{array}{c}\boldsymbol{p} \text { - } \\
\text { value }\end{array}$ \\
Kerja & Mengemudi & & \\
\hline
\end{tabular}
$\mathrm{p}=0,024<\mathrm{a}=0,05$ yang dapat disimpulkan bahwa terdapat hubungan masa kerja dengan tindakan mengemudi tidak aman pada supir Bus Sampri Trayek Medan-Dolok Sanggul. 
e. Hubungan Lama Istirahat dengan Tindakan Mengemudi Tidak Aman pada Supir Bus Sampri Trayek Medan - Dolok Sanggul

Hubungan masa kerja dengan tindakan mengemudi tidak aman pada Supir Bus Sampri Trayek Medan - Dolok Sanggul tahun 2018, dapat dilihat pada tabel 5 berikut:

Tabel 5. Hubungan Lama Istirahat dengan Tindakan Mengemudi Tidak Aman pada Supir Bus Sampri Trayek Medan - Dolok Sanggul

\begin{tabular}{|c|c|c|c|c|c|c|c|}
\hline \multirow{4}{*}{ Lama Istirahat } & \multicolumn{4}{|c|}{ Tindakan Mengemudi } & \multirow{2}{*}{\multicolumn{2}{|c|}{ Total }} & \multirow{3}{*}{ p-value } \\
\hline & \multicolumn{4}{|c|}{ Tidak Aman } & & & \\
\hline & \multicolumn{2}{|c|}{ Ringan } & \multicolumn{2}{|c|}{ Berat } & & & \\
\hline & n & $\%$ & n & $\%$ & n & $\%$ & \multirow{4}{*}{0,024} \\
\hline$\leq 15$ Menit & 10 & 52,6 & 9 & 47,4 & 19 & 100,0 & \\
\hline$>15$ Menit & 12 & 92,3 & 1 & 7,7 & 13 & 100,0 & \\
\hline Total & 22 & 68,8 & 10 & 31,2 & 32 & 100 & \\
\hline
\end{tabular}

Tabel 5 di atas menunjukkan bahwa nilai $\mathrm{p}=0,024<\mathrm{a}=0,05$ yang dapat disimpulkan bahwa terdapat hubungan lama istirahat dengan tindakan mengemudi tidak aman pada supir Bus Sampri Trayek Medan-Dolok Sanggul.

\section{f. Hubungan Jadwal Kerja dengan} Tindakan Mengemudi Tidak Aman pada Supir Bus Sampri Trayek Medan - Dolok Sanggul

Hubungan jadwal kerja dengan tindakan mengemudi tidak aman pada Supir Bus Sampri Trayek Medan - Dolok Sanggul tahun 2018, dapat dilihat pada tabel 6 berikut:

Tabel 6. Hubungan Jadwal Kerja dengan Tindakan Mengemudi Tidak Aman pada Supir Bus Sampri Trayek Medan - Dolok Sanggul

\begin{tabular}{|c|c|c|c|c|}
\hline \multirow[t]{2}{*}{$\begin{array}{c}\text { Jadwal } \\
\text { Kerja }\end{array}$} & \multicolumn{2}{|c|}{$\begin{array}{c}\text { Tindakan } \\
\text { Mengemudi } \\
\text { Tidak Aman }\end{array}$} & \multirow[t]{2}{*}{ Total } & \multirow{2}{*}{$\begin{array}{c}\text { p-supir yang tidak menggunakan sabuk } \\
\text { valtpengaman atau safety belt dan menggunakan } \\
\boldsymbol{e} \text { handphone pada saat mengemudi akan } \\
\text { mengakibatkan kecelakaan lalu lintas. Selain } \\
\mathbf{0 , 0 3} \text { berdampak pada pengemudi sendiri juga }\end{array}$} \\
\hline & Ringan & Berat & & \\
\hline
\end{tabular}

\section{PEMBAHASAN}

\section{a. Hubungan Lama Kerja dengan Mengemudi Tidak Aman pada Supir Bus Sampri Trayek Medan-Dolok Sanggul}

Hasil penelitian menunjukkan bahwa terdapat hubungan lama kerja dengan tindakan mengemudi tidak aman pada Supir Bus Sampri Trayek Medan - Dolok Sanggul Tahun 2018.

Durasi mengemudi yang tidak sesuai dengan standarnya yaitu 9 jam per hari atau 48 jam per minggu menyebabkan pengemudi mengalami kelelahan.

Setiap orang memiliki tingkat kemampuan fisik yang berbeda-beda. Tubuh manusia juga mempunyai batasan untuk bekerja secara terus menerus. Manusia akan mengalami kelelahan baik fisik maupun mental apabila melebihi batas kemampuan tubuhnya. Berdasarkan UU RI No. 22 Tahun 2009 tentang Lalu Lintas Dan Angkutan Jalan pasal 90 ayat 2 menyatakan bahwa waktu kerja bagi pengemudi kendaraan bermotor umum maksimal 8 jam setiap hari.

Temuan di lapangan, Supir Bus Sampri mengemudi dengan durasi di atas 8 jam sehari, kecepatan $80-120 \mathrm{~km} /$ jam, perilaku /pengaman atau safety belt dan menggunakan berdampak pada pengemudi sendiri juga 
berdampak pada penumpang dan perusahaan otobus/transport.

\section{b. Hubungan Masa Kerja dengan Mengemudi Tidak Aman pada Supir Bus Sampri Trayek Medan-Dolok Sanggul}

Hasil penelitian menunjukkan bahwa terdapat hubungan masa kerja dengan tindakan mengemudi tidak aman pada Supir Bus Sampri Trayek Medan - Dolok sanggul tahun 2018. Hasil penelitian Dahlan (2013) yang mengatakan tidak ada hubungan antara masa kerja dan perilaku safety driving.

Semakin lama masa kerja pengemudi, semakin banyak pengalaman yang dimiliki oleh pengemudi makaa menjadikan seseorang tersebut bertambahnya kemampuan, keterampilan dan pengetahuan dalam berkendara sehingga cenderung akan bertindak aman saat berkendara yang dapat mencegah terjadinya kecelakaan lalu lintas (Dewar, 2007; Prasetya, 2016). Pengemudi yang memiliki masa kerja yang sedikit atau pengemudi yang masih baru biasanya masih belum mengetahui secara mendalam seluk beluk berkendara dengan selamat.

Semakin lama masa kerja seseorang maka semakin tinggi tingkat adaptasi tubuh terhadap kelelahan. Semakin lama seseorang bekerja maka perasaan terbiasa dengan pekerjaan yang dilakukan akan berpengaruh terhadap tingkat daya tahan tubuhnya terhadap kelelahan yang dialaminya.

\section{c. Hubungan Lama Istirahat dengan Mengemudi Tidak Aman pada Supir Bus Sampri Trayek Medan-Dolok Sanggul}

Berdasarkan hasil penelitian ini, dapat diketahui ada hubungan lama istirahat dengan tindakan mengemudi tidak aman pada Supir Bus Sampri trayek Medan - Dolok sanggul tahun 2018.

Adapun faktor yang mempengaruhinya yaitu jumlah penumpang dan jarak antar bus dan lama istiraha. Pemanfaatan waktu istirahat kerja dengan baik dapat membantu dalam menjaga kondisi tubuh agar tidak mengalami kelelahan (Firmansyah, 2013).

Menurut UU RI No 22 Tahun 2009 tentang Lalu Lintas dan Angkutan Jalan pasal 80 ayat 3 menyebutkan bahwa pengemudi kendaraan umum wajib beristirahat setengah jam setelah mengemudi selama empat jam berturut-turut.

Kualitas lama istirahat yang kurang baik dapat menyumbang terjadinya kelelahan, kewaspadaan, keselamatan, gangguan yang kompleks ketika bekerja serta hilangnya kesadaran. Supir memberikan kesempatan tubuhnya untuk beristirahat sejenak. Kemudian kembali melanjutkan pekerjaan dengan tubuh yang kembali siap dan segar. Hal ini dapat mengurangi tingkat kelelahan yang dialami pekerja pada saat bekerja.

\section{d. Hubungan Jadwal Kerja dengan Mengemudi Tidak Aman pada Supir Bus Sampri Trayek Medan-Dolok Sanggul}

Hasil penelitian menunjukkan bahwa ada hubungan jadwal kerja dengan tindakan mengemudi tidak aman pada Supir Bus Sampri Trayek Medan - Dolok sanggul tahun 2018. Penelitian yang dilakukan oleh Sherry L Baron dan Sang Woo Tak dalam Astuti yang menyatakan bahwa pengemudi yang bekerja pada malam hari akan cenderung berperilaku aman dalam mengemudi. Seseorang yang bekerja pada shift sore cenderung akan mengalami kelelahan karena pagi harinya sudah beraktivitas sehingga peluang untuk berperilaku tidak aman semakin besar.

Jadwal kerja merupakan sistem aturan pengaturan waktu kerja yang memungkinkan pekerja berpindah dari satu waktu ke waktu yang lain setelah periode tertentu, dengan cara bergantian antara pekerja yang satu dengan pekerja yang lain (Suma'mur, 2009). Jadwal shift kerja menuntut pekerja untuk mengesampingkan jam internal biologis yang 
mengatur aktivitas siang dan malam dari manusia. Shift kerja memaksa untuk mengubah jam tidurnya berdasarkan waktu kerja dan waktu istirahat, sehingga ini dapat mengganggu siklus normal dari aktivitas fisik.

Hasil pengamatan yang dilakukan pada saat penelitian, pekerja yang bekerja pada shift sore lebih berpengaruh negatif terhadap kondisi pekerja dibanding shift pagi karena pola siklus hidup manusia pada sore hari umumnya digunakan untuk istirahat. Namun karena banyak bekerja pada shift sore maka tubuh dipaksa untuk mengikutinya. Hal ini relatif cenderung mengakibatkan terjadinya kesalahan atau kelalaian pekerja, dan kecelakaan.

\section{KESIMPULAN}

Adapun kesimpulan pada penelitian ini yaitu:

1. Ada hubungan lama kerja, masa kerja, lama istirahat dengan tindakan mengemudi tidak aman pada Supir Bus Sampri Trayek Medan - Dolok Sanggul Tahun 2018 dengan nilai $p(0,024)<\mathrm{a}(0,05)$.

2. Ada hubungan jadwal kerja dengan tindakan mengemudi tidak aman pada Supir Bus Sampri Trayek Medan - Dolok Sanggul Tahun 2018 dengan nilai $p$ $(0,035)<a(0,05)$.

\section{DAFTAR PUSTAKA}

Dahlan, Y. 2013. Faktor - faktor yang berhubungan dengan safety driving pada supir bus trayek ManadoSemarang di Terminal Malalayang. Skripsi. Fakultas Kesehatan Masyarakat Universitas Sam Ratulangi Manado

Direktorat Jenderal Perhubungan Darat. (2014). Departemen Perhubungan Darat Dalam Angka 2014. Diakses 27 Oktober 2017 dari: http://www.hubdat. web.id.websitk/file/dktj.pdf
Firmansyah, A . 2013. Faktor yang berhubungan dengan perilaku safety driving pada pengemudi mobil pengangkut semen curah di PT. Prima Karya Manuggal (PKM) Kab. Pangkep Tahun 2013

Hastuti H.A. (2013). Hubungan antara Self Regulated Behavior dengan Unsafe Behavior pada Sopir Bus di Kota Semarang. Journal. Semarang. Jurusan Psikologi Fakultas Ilmu Pendidikan Universitas Negeri Semarang

Prasetya, A 2016. Faktor yang berhubungan dengan safety driving pada pengemudi bus ekonomi trayek Semarang Surabaya di Terminal Terboyo Semarang (Online), Vol. 4, N0 3 (http://ejournal-s

I. undip.ac.id/index.php/jkm diakses tanggal 20 Februari 2018

Putra, Aprian E . 2015 Faktor-Faktor yang Berhubungan dengan Perilaku Aman Pengemudi Dump Truck PT. $X$ District MTBU Tanjung Enim, Sumatera Selatan Tahun 2015. Diakses dari: http://digilib.ui.ac.id tanggal 08 Maret 2018

Suma'mur. 2009. Hiegiene Perusahaan dan Keselamatan Kerja. Jakarta : CV Sagung Seto

Undang-Undang No. 22 Tahun 2009 tentang Lalu Lintas dan Angkutan Jalan. Diakses melalui www.polri.go.id tanggal 29 Oktober 2017 